\title{
Jogo Minecraft como aliado no processo de ensino e aprendizagem da geometria espacial
}

Paula Boito

paulinhaboito@gmail.com 0000-0002-2410-6286

Universidade de Passo Fundo, Passo Fundo, Rio Grande do Sul, Brasil.

Juliano Tonezer da Silva tonezer@upf.br

0000-0003-3476-6488

Universidade de Passo Fundo, Passo

Fundo, Rio Grande do Sul, Brasil.

\begin{abstract}
RESUMO
Este artigo tem por objetivo discutir as potencialidades do jogo digital Minecraft como suporte ao ensino e aprendizagem de elementos introdutórios da Geometria Espacial no sexto ano do Ensino Fundamental. Para esta pesquisa, utilizou-se como aportes teóricos o Construcionismo proposto por Seymour Papert (1985), além do diálogo problematizador e contextualização do saber defendidos por Paulo Freire (1996). Dessa forma, desenvolveuse uma sequência de atividades estruturada em doze encontros, agregando a tecnologia do jogo Minecraft aliado a outras mídias e elementos usualmente utilizados. A pesquisa-ação pautou-se na análise de dados coletados: Diário de Bordo, transcrição de diálogos, fotos, vídeos e relatórios preenchidos pelos estudantes. A avaliação da pertinência dessa proposta pedagógica ocorreu com base nessas análises. Como resultado, a pesquisa apontou sua relevância para a aprendizagem da geometria, além de mostrar-se pertinente em termos de participação e comprometimento da turma, abrindo um canal de diálogo entre professor e alunos.
\end{abstract}

PALAVRAS-CHAVE: Minecraft. Geometria Espacial. Construcionismo. Diálogo Problematizador. Contextualização do Saber. 


\section{INTRODUÇÃO}

Este trabalho aborda uma discussão recorrente nos grupos de pesquisa em Educação Matemática: o uso de tecnologias como recurso metodológico nos anos finais do ensino fundamental. Para isso, aliamos estratégias já consagradas na sala de aula de Matemática, como a utilização de dobraduras dos sólidos geométricos em papel, atividades de observação de campo e construção de maquetes, com o uso de jogo computacional Minecraft e demais aparatos tecnológicos, como câmeras de fotografia e celulares. Isso, num cenário de ensino e aprendizagem da Geometria, por sua importância na leitura interpretativa do mundo, que extrapola o universo matemático. Como embasamento teórico utilizou-se o Construcionismo preconizado por Seymour Papert e as contribuições de Paulo Freire, relacionadas ao diálogo problematizador e a contextualização do saber, uma vez que a relação comunicativa entre os pares em torno do conteúdo abordado potencializa o aprendizado de maneira mais ampla e significativa.

Neste contexto, a temática principal da pesquisa é a aprendizagem da Geometria Espacial no sexto ano do ensino fundamental ancorada nas tecnologias digitais, buscando facilitar a transição entre os objetos concretos e abstratos referentes aos entes geométricos e potencializar o entendimento de conceitos inerentes ao estudo da Geometria espacial. Referimo-nos como "concretos" os objetos que podem ser manipulados fisicamente e como "abstratos" os artefatos virtuais. Pois, a relação dialética entre a realidade do sujeito e sua consciência histórica é bastante discutida em Freire e se aplica à relação entre o concreto e o abstrato. O concreto como sendo a visão empírica de mundo desse sujeito e o abstrato na escolha dos saberes passíveis de serem mobilizados em outros contextos, resultando na intervenção daquela realidade.

Essa temática se justifica devido ao fato de que ensinar Matemática implica o estímulo ao pensamento independente, à elaboração e análise de estratégias para resolver situações adversas, criatividade na busca por soluções de problemas. Pois, quando no sexto ano do ensino fundamental o assunto é a Geometria Espacial, o ensino torna-se muitas vezes um desafio ao professor, onde a transição da ideia do concreto para o abstrato e do abstrato de volta ao concreto não é algo que ocorre para todos naturalmente. Para auxiliar seu trabalho em sala de aula, é pertinente que o docente utilize recursos que fazem parte do cotidiano dos alunos.

Aliado a esta temática, procuramos investigar as potencialidades e limitações do uso do jogo computacional Minecraft ao ensinar as formas geométricas tridimensionais no sexto ano do ensino fundamental. Quanto à abordagem, a pesquisa foi do tipo qualitativa, de natureza aplicada. Classificada como pesquisaação educacional, de caráter exploratório. A avaliação da pertinência da proposta pedagógica ocorreu pela análise dos instrumentos de coleta: Diário de Bordo, transcrição de diálogos, fotos, vídeos e relatórios compostos por questionários semiestruturados respondidos ao final de cada encontro. A proposta pedagógica consistiu na aplicação de uma sequência de atividades com doze encontros, cujo tema principal foi o conteúdo de Geometria Espacial. Para isso, utilizamos estratégias metodológicas abrangendo diversos recursos didático-pedagógicos, como trabalho de campo na busca por figuras geométricas no entorno da sala de aula, planificação e construção de hexaedros em papel sulfite 40 , construção de artefato em ambiente virtual (no caso, através do Minecraft), confecção de maquete e seminários. Iniciamos com uma pesquisa de campo feita em pequenos 
grupos para observação, identificação e registro de sólidos geométricos com o uso de smartphones com câmeras fotográficas. Após esse momento, conversamos sobre como poderíamos descrever esses objetos, diferenciando os sólidos geométricos. Na sequência, construímos, também em grupos, artefatos virtuais com a utilização de jogo eletrônico Minecraft e posterior planificação e construção de maquete relacionada ao tema. Durante esse processo, os estudantes, em seus grupos, fizeram a análise inicial dessa proposta, respondendo a pequenos questionários semiestruturados contidos no relatório entregue a cada grupo. Por fim, estão descritos a seguir todo esse processo, do embasamento teórico, aplicação da sequência de atividade, análise de resultados e considerações finais.

\section{REFERENCIAL TEÓRICO}

As reflexões acerca das relações existentes entre o aluno, o professor e o conhecimento no que se refere a ensinar e aprender Matemática fazem parte de um processo de amadurecimento do educador matemático. É preciso estar atento às novas formas de produção e apropriação do saber científico. Assim, buscando compreender essas relações, no contexto de jogos digitais, utilizamos como referencial teórico o Construcionismo, o diálogo problematizador e a contextualização do saber científico.

\section{Construcionismo}

Com a chegada da tecnologia digital à sociedade, e por consequência à escola, percebeu-se a necessidade de repensar e complementar as teorias norteadoras do processo de ensino e aprendizagem. Até então, num contexto de década de 70/80, a escola trazia a abordagem Instrucionista de Skinner (1972), em que o aluno era mero receptor do conhecimento transmitido pelo professor e o computador incorporado ao ambiente educacional como uma máquina de ensinar. Essa perspectiva estava fundamentada no princípio de que a ação de ensinar (instruir) é inerente à transmissão de informação ao aluno e seu sucesso estava relacionado ao aperfeiçoamento das técnicas para transmitir tal conhecimento.

Em oposição ao Instrucionismo, Seymour Papert (1985) propôs uma teoria educacional denominada de Construcionismo. Assim, enquanto teoria da aprendizagem, o Construcionismo é uma reconstrução do Construtivismo, no sentido de que o saber é adquirido pelo próprio sujeito da aprendizagem ao passo em que este se desenvolve cognitivamente de forma motivada, utilizando como suporte um artefato tecnológico com o qual interage. Ainda, no Construcionismo a interação aluno-objeto ocorre com a utilização do computador mediada por uma linguagem de programação, gerando a construção de um objeto de interesse do aprendiz.

\section{Paulo Freire: contextualização do saber e diálogo problematizador}

A proposta educativa de Paulo Freire sempre foi ancorada na superação das desigualdades sociais para o desenvolvimento de uma consciência crítica. Procurava estabelecer a relação dialética do aprendido com o mundo, utilizando principalmente os aspectos históricos e a discussão das contradições presentes na realidade, ou seja, uma "práxis que, sendo reflexão e ação verdadeiramente transformadora da realidade, é fonte de conhecimento reflexivo e criação." (FREIRE, 1985, p. 108). 
Neste sentido, contextualizar pode ser entendido como a ação de levar aos estudantes estratégias baseadas em realidades que contenham elementos capazes de dar significado ao conteúdo trabalhado. Dessa forma, contextualizar a Matemática significa construir com os alunos elaborações pautadas no conteúdo escolar e amparadas no contexto histórico e social, possibilitando ao aprendiz a construção de conhecimentos partindo de sua própria atividade cognoscitiva. A forma com que abordamos a contextualização da Matemática, neste estudo está de acordo com Freire à medida que

[...] nas condições de verdadeira aprendizagem os educandos vão se transformando em reais sujeitos da construção e da reconstrução do saber ensinado [...]. Percebe-se, assim, que faz parte da tarefa docente não apenas ensinar conteúdos, mas também ensinar a pensar certo (FREIRE, 1996, p. 26).

A principal contribuição da contextualização é a de colocar as questões da aprendizagem no centro da atenção do educador. Desse modo, o processo de comparar e contextualizar o conteúdo escolar para o espaço de uma turma em particular tem respaldo teórico no método dialógico de Freire:

[...] o exercício de pensar o tempo, de pensar a técnica, de pensar o conhecimento enquanto se conhece, de pensar o quê das coisas, o para quê, o como, o em favor de quê, de quem, o contra quê, o contra quem são exigências fundamentais de uma educação democrática à altura dos desafios do nosso tempo (FREIRE, 2000, p. 102).

Em complemento, o diálogo problematizador refere-se à socialização dos saberes de cada um, modificando e aprimorando os conhecimentos de origem. $\mathrm{O}$ diálogo é o alicerce em que construímos o conhecimento. Esse encontro de reflexões individuais ganha força à medida que as ideias são confrontadas, com a intenção de produzir novos saberes. Ou seja,

[...] deveríamos entender o "diálogo" não como uma técnica apenas que podemos usar para conseguir obter alguns resultados. Também não podemos, não devemos, entender o diálogo como uma tática que usamos para fazer dos alunos nossos amigos. Isso faria do diálogo uma técnica para a manipulação, em vez de iluminação. Ao contrário, o diálogo deve ser entendido como algo que faz parte da própria natureza histórica dos seres humanos. [...] Isto é, o diálogo é uma espécie de postura necessária, na medida em que os seres humanos se transformam cada vez mais em seres criticamente comunicativos. O diálogo é o momento em que os humanos se encontram para refletir sobre sua realidade tal como a fazem e re-fazem (FREIRE; SHOR, 2000, p. 122-123).

Quando esses diálogos são provocados intencionalmente no ambiente escolar, mesmo com as interferências e a mediação do professor, é o estudante quem chega às próprias conclusões. A busca pelo conhecimento científico, pela pesquisa, pela utilização de ferramentas e recursos metodológicos pode ser incorporada na busca pela resolução de situações propostas em sala de aula. Assim, o estudante tem a chance de perceber a importância da pesquisa mesmo nos anos iniciais de sua trajetória escolar. 


\section{APLICAÇÃO DO PRODUTO EDUCACIONAL}

A aplicação da sequência de atividades ocorreu em uma escola no município de Tapejara, nordeste do Rio Grande do Sul, no período entre 31 de julho e 21 de setembro de 2017. A turma na qual foi realizada a aplicação era composta por nove estudantes do sexto ano do Instituto de Educação de Tapejara.

Em síntese, a aplicação da sequência de atividades foi realizada em doze encontros, com duração média de um período letivo (cinquenta minutos). Os alunos foram divididos em pequenos grupos, buscando priorizar a interação entre os alunos, tendo como instrumentos de trabalho o jogo computacional Minecraft, além de smartphones, material concreto, material dourado, Geoplano e materiais de desenho. Os encontros foram estruturados de modo a que houvesse interação entre atividades que ocupassem vários ambientes da escola, como pátio, sala de aula e laboratório de informática, através da busca de objetos geométricos, construção de artefato virtual, construção física do artefato e por fim a comparação entre os processos de construção. A descrição dos encontros teve como base o Diário de Bordo (ZABALZA, 2004), elaborado após cada encontro da aplicação da sequência de atividades, bem como os dados coletados: observações, relatórios dos grupos, artefatos elaborados pelos alunos, imagens e transcrição dos diálogos capturados em vídeos dos encontros. No decorrer dos relatos, usamos identificações compostas por uma letra maiúscula (A para aluno e G para grupo) e um número, para manter o anonimato. Com isso, identificamos os grupos por G1, G2 e G3 e os alunos por A1 a A9.

Iniciamos o primeiro encontro com a problematização dos conhecimentos prévios dos alunos quanto ao conjunto de elementos pertencentes ao estudo da geometria. Para isso, foram lançados questionamentos quanto aos critérios observáveis no intuito de classificar um ente matemático como sendo ou não alvo dos estudos geométricos. Esse primeiro momento poderia trazer indícios da clareza dos alunos sobre os elementos estudados na geometria plana e suas diferenças dos objetos da geometria espacial, sendo um importante aliado no planejamento das atividades subsequentes. Quanto a isso, percebemos que os alunos já traziam essa noção de que a geometria estuda as formas, mas ainda não internalizaram, por exemplo, que as formas quadrado e cubo não são a mesma figura, embora tenham relação uma com a outra. Isso ficou evidente nos exemplos de objetos geométricos fotografados pelos grupos. O primeiro encontro teve como objetivo a apresentação e organização do projeto: separação dos pequenos grupos escolhidos por sorteio, organização das tarefas que cada um desempenharia ao longo de todo o projeto e confeç̧ão da identificação visual de cada grupo (capa para o Relatório constando nome e desenho, acordado entre os integrantes de cada grupo); formaram-se três grupos com três integrantes em cada equipe. Em seguida, ocorreu o trabalho de campo, que consistiu na escolha e fotografias de objetos pelos grupos para análise e posterior classificação geométrica, conforme NACARATO (2014).

No segundo encontro, o objetivo foi a realização de um Seminário, no qual cada grupo apresentou as imagens capturadas, com sua classificação geométrica. As apresentações foram preparadas e executadas no período do encontro. Com base na escolha das figuras, observamos nos grupos a preocupação em retratar a característica tridimensional dos objetos através de imagens em perspectiva. No Seminário de apresentação desta etapa, explicaram que há diferença entre objetos 
como o quadro branco, que representa só um plano e uma latinha, que tem profundidade, por exemplo. Além disso, comentaram que praticamente tudo tem essa profundidade. Quanto à classificação dos objetos, a característica mais mencionada pelos grupos é a de que "poliedros não rolam". Isso nos permitiu constatar que, na prática, há alguma clareza quanto à classificação dos entes geométricos utilizados na apresentação.

O terceiro encontro objetivou a exploração do Jogo Minecraft. No laboratório de informática, os grupos aprenderam a efetuar o download do jogo, para que pudessem jogar em casa, com a permissão dos responsáveis. No caso da escola, a instalação foi realizada previamente pelo responsável pela manutenção dos computadores. Nesse momento, os alunos com mais experiência no Minecraft auxiliaram àqueles que não haviam jogado ainda. Efetuaram o cadastro dos grupos, fazendo anotações no relatório para consultas posteriores (o login, por exemplo). Foram orientados pela professora quanto à escolha do modo de jogo, para a opção Single Player (um jogador) e o modo Survival (sobrevivência).

No quarto encontro os alunos tiveram a tarefa de construir um cercado virtual para abrigar animais, que poderia ser feito com qualquer matéria-prima disponível, porém suas medidas de comprimento e largura deveriam obedecer aos valores de área e perímetro especificados pela professora. 0 desafio desse encontro consistiria não na execução, mas em calcular medidas específicas para atender às exigências estabelecidas, a saber: perímetro equivalente a 40 unidades de comprimento e superfície de 96 unidades de área. Para isso, teriam de perceber que o formato retangular era a opção mais fácil de produzir, o que realmente aconteceu: os alunos fizeram vários questionamentos a respeito do que o problema exigia que fosse feito. Por tentativas feitas no jogo e no papel, conseguiram encontrar os valores de 12 e 8 unidades para as medidas dos lados de um retângulo. $O$ dinamismo proporcionado pelo computador na visualização e transformação com resultados imediatos torna-se um instrumento cognitivo. A possibilidade de experimentar, errar e construir estratégias de solução de situações adversas faz do uso de tecnologias um importante recurso pedagógico. No âmbito das tecnologias computacionais, Borba e Villarreal (2005) ressaltam também a importância da visualização para a Educação Matemática, por tratar-se de uma forma alternativa para a compreensão do conhecimento matemático, e um suporte para que o aluno resolva problemas, especialmente em Geometria. Além disso, no encontro, a conversa entre os alunos para descobrir como vencer os obstáculos foi constante: a todo o momento perguntavam "como faço para construir uma mesa?" "Como faço a cama?", sempre respondido prontamente por algum colega cujo projeto estava adiantado. Orientei os grupos a fazer buscas na internet se necessário.

O quinto encontro iniciou com uma conversa em sala de aula sobre as tarefas a serem executadas no restante do projeto, que incluiriam a busca de modelos para casas do Minecraft e tutoriais de construção, disponíveis na internet. Em seguida, haveria busca de matéria-prima virtual no micromundo e início da construção da casa. Esse encontro talvez fosse o mais importante em termos de socialização do saber e estreitamento das relações entre os componentes dos grupos. Os alunos deveriam tomar decisões importantes, cujos reflexos estariam presentes nas demais fases do projeto. Por esse motivo, e para intermediar possíveis conflitos, as intervenções da professora nessa etapa foram mais frequentes. Houve várias trocas entre os integrantes de cada grupo e entre os 
grupos, quanto ao tipo de material que seria melhor para construir determinada estrutura, ou como resolver um problema de superpopulação de lobos, por exemplo. Os alunos mais experientes no jogo responderam prontamente às dúvidas dos colegas quanto aos comandos e atalhos.

O sexto encontro foi destinado à construção dos alicerces da casa. Os grupos trabalharam na colocação das paredes, aberturas, telhado, divisão dos cômodos. Cada grupo usou um computador, mas se deslocaram várias vezes pelo laboratório para conversar com os demais colegas sobre seus projetos. Como estavam trabalhando no mesmo computador, os integrantes de um mesmo grupo revezavam-se nas tarefas: um operava os comandos enquanto houve a socialização das ideias entre os demais.

O sétimo encontro também foi utilizado para a construção da casa. Neste momento, a estrutura estava pronta (paredes, aberturas e telhado) e a tarefa foi de construir os móveis e os objetos de decoração. Para isso, os grupos buscaram tutoriais na internet e conversaram sobre o assunto entre os colegas. Houve, nesse encontro, momentos em que o grupo precisou decidir sobre aspectos importantes da casa, como quantidade de objetos decorativos, por exemplo. Essas decisões foram tomadas em um ambiente descontraído e respeitoso. Finalizamos o encontro com as casas montadas e mobiliadas, com exceção de poucos detalhes.

No oitavo encontro, os grupos já estavam finalizando os projetos virtuais, detendo-se aos detalhes: elementos de decoração e jardim, em que o grupo adornou o jardim com flores.

No nono encontro, em sala de aula, foi retomada a proposta de escala, já estudada no trimestre anterior. Para isso, a turma fez duas atividades, sendo a primeira de desenhar um objeto em tamanho natural (escala 1:1) e depois reduzilo à escala 1:2 e o segundo, ampliar em escala 2:1. Como foi uma tarefa executada com facilidade por quase todos os alunos, partimos para a ideia da planificação do cubo. Para isso, cada grupo recebeu uma caixinha de papelão e uma folha de papel A4, e o desafio de confeccionar um molde que satisfizesse, ao mesmo tempo, as duas condições da atividade: deveria ter as características de um hexaedro e, ao mesmo tempo, desperdiçar o mínimo de papel. Para auxiliar a visualização, além das caixinhas que eles poderiam manipular à vontade, abrir e até partir em pedaços, foram disponibilizados cubos do Material Dourado, com arestas medindo $4 \mathrm{~cm}$ e $10 \mathrm{~cm}$, para manipulação e comparação de tamanhos. O restante da atividade transcorreu sem intervenções da professora. Os alunos abriram, recortaram e fizeram os moldes baseados nas caixinhas de papelão.

O passo seguinte foi o da escolha das medidas que cada grupo escolheria para construir sua maquete. Como elas estariam sobre um suporte de isopor, com medidas $100 \mathrm{~cm} \times 50 \mathrm{~cm} \times 3 \mathrm{~cm}$, as construções deveriam ser proporcionais à área disponível e ainda deveriam suportar o peso total. Comparando os cubos do material dourado, os alunos chegaram à conclusão de que arestas com $10 \mathrm{~cm}$ (cubo maior) gerariam casas desproporcionais ao tamanho do isopor, da mesma forma que cubos com arestas de $1 \mathrm{~cm}$. Então chegaram ao consenso e escolheram a medida de $4 \mathrm{~cm}$. O próximo passo foi confeccionar um novo molde, dessa vez com as medidas definitivas, organizadas na folha A4, para futura reprodução. Os grupos ainda mostraram preocupação quanto ao desperdício. Depois de construídos os moldes da planificação, buscaram outra folha A4, para acomodar o molde de tal forma que sobrasse pouco papel. Depois dos moldes prontos, buscamos moldes 
de figuras do jogo, o que trouxe uma nova gama de ideias para o projeto da maquete, com detalhes que passaram despercebidos até esse ponto do trabalho. Ao final do encontro, houve ainda a decisão quanto ao material que seria utilizado na confecção dos cubos. Os alunos poderiam escolher entre papel colorido, papel pardo ou ainda papel branco, que deveria ser pintado por eles. Todos optaram pelo papel branco.

O décimo encontro foi dividido em duas etapas: a primeira, em sala de aula, com novos cálculos referentes à quantidade de blocos que cada grupo precisaria para a construção da maquete física; a segunda etapa ocorreu no laboratório de informática, com a verificação dos detalhes e tamanhos de cada objeto a ser reproduzido. Como era previsível, os alunos não tinham dados suficientemente detalhados em seus relatórios para a construção das réplicas, percebendo somente no momento de estimar a quantidade de blocos da maquete. Desta forma, no segundo momento, fomos ao laboratório, cada grupo com seu relatório em mãos, para anotar o que seria necessário para concluir a tarefa do dia. Percebemos que o detalhamento foi bem maior depois desse primeiro contato com a maquete.

O décimo primeiro encontro foi destinado à montagem dos cubos em folhas de papel sulfite. Todos trabalharam juntos na pintura e colagem dos objetos. Esta etapa foi concluída no turno inverso aos encontros.

O último encontro da sequência de atividades foi dedicado à socialização dos projetos e à exposição das maquetes no corredor principal da escola. A seguir, a Figura 1, que ilustra a compilação das imagens das maquetes do grupo G1 praticamente pronta, seguida das estruturas virtuais capturadas em vídeo durante o Encontro 8. Alguns detalhes não foram acrescentados, pois seria necessário que houvesse, pelo menos, mais um período de aula para serem concluídos. Mesmo assim, a maior parte estava feita e os grupos explicaram o que faltou e como seria terminado.

Figura 1 - Seminário final

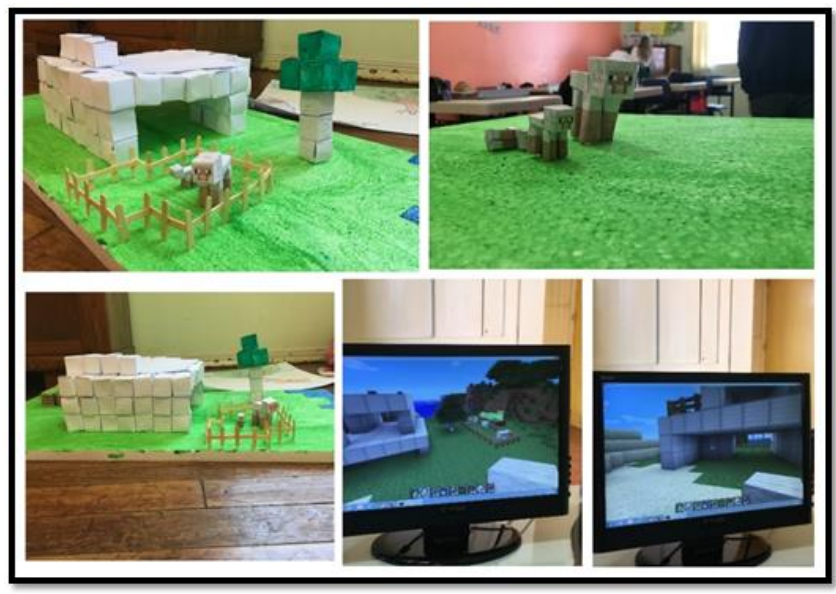

Fonte: Autores (2017).

Por meio das imagens feitas no ambiente físico e virtual, sintetizados na Figura 1 , percebemos semelhanças principalmente nos pontos que mais chamaram a atenção dos grupos durante o projeto, pois os alunos não tiveram acesso aos vídeos das construções virtuais durante a confecção das maquetes. 


\section{ANÁLISE DE DADOS}

Segundo os Parâmetros Curriculares Nacionais - PCNs (1998, p. 72-73) para o terceiro ciclo do ensino fundamental ( 60 e 70 anos), é importante considerar, nas atividades escolares, determinadas competências e habilidades que envolvam espaço e forma, bem como grandezas e medidas. Então, buscamos, nesta pesquisa, promover atividades de forma a proporcionar aos estudantes a aquisição de algumas dessas competências e habilidades, com vistas a atingir o objetivo principal, que é o de investigar as potencialidades do uso do jogo Minecraft no processo de ensino e aprendizagem da Geometria Espacial em uma turma de sexto ano do ensino fundamental. Também, contemplar alguns dos objetivos específicos, como o uso de material concreto como elemento dos processos de ensino e aprendizagem, a transição da ideia de objeto concreto para o pensamento abstrato, o uso de diferentes mídias digitais, construção de um artefato virtual e construção de maquetes partindo de modelos virtuais.

Nesse sentido, optamos por analisar os dados coletados durante toda a sequência de atividades, para cada aluno (um aluno de cada grupo, totalizando três alunos), para cada item referente ao que é preconizado nos PCNs (Texto adaptado dos PCNs (BRASIL, 1998, p. 72-77) para essa etapa (Quadro 1).

\section{Quadro 1 - Quadro-síntese dos itens dos PCNs}

\section{Quadro-síntese dos itens dos PCNs}

\begin{tabular}{|c|c|}
\hline I1 & $\begin{array}{c}\text { Distinção, em contextos variados, de figuras bidimensionais e tridimensionais, } \\
\text { descrevendo algumas de suas características, estabelecendo relações entre } \\
\text { elas e utilizando nomenclatura própria. }\end{array}$ \\
\hline 12 & $\begin{array}{l}\text { Classificação de figuras tridimensionais e bidimensionais, segundo critérios } \\
\text { diversos, como: corpos redondos e poliedros; prismas, pirâmides e outros } \\
\text { poliedros; círculos, polígonos e outras figuras; número de lados dos polígonos; } \\
\text { medidas de lados. }\end{array}$ \\
\hline 13 & $\begin{array}{c}\text { Reconhecimento de grandezas como comprimento e superfície e identificação } \\
\text { de unidades adequadas (padronizadas ou não) para medi-las, fazendo uso de } \\
\text { terminologia própria. }\end{array}$ \\
\hline 14 & $\begin{array}{l}\text { Compreensão da noção de medida de superfície e de equivalência de figuras } \\
\text { planas por meio da composição e decomposição de figuras. }\end{array}$ \\
\hline 15 & $\begin{array}{l}\text { Cálculo da área de figuras planas pela decomposição e/ou composição em } \\
\text { figuras de áreas conhecidas, ou por meio de estimativas. }\end{array}$ \\
\hline 16 & Identificação de diferentes planificações de alguns poliedros. \\
\hline 17 & $\begin{array}{l}\text { Ampliação e redução de figuras planas segundo uma razão e identificação dos } \\
\text { elementos que não se alteram (medidas de ângulos) e dos que se modificam } \\
\text { (medidas dos lados, do perímetro e da área). }\end{array}$ \\
\hline 18 & $\begin{array}{l}\text { Utilização de instrumentos de medida, como régua, escalímetro, esquadro, } \\
\text { trena, selecionando os instrumentos e unidades de medida adequadas à } \\
\text { precisão que se requerem em função da situação-problema. }\end{array}$ \\
\hline
\end{tabular}

Fonte: Autores (2017).

Com o objetivo de avaliar a viabilidade da proposta pedagógica e verificar indícios de aprendizagem, escolhemos um integrante de cada um dos três grupos para realizar a análise dos dados coletados ao longo da aplicação da sequência de 
atividades. A seguir, relatamos um item da análise correspondente a cada estudante.

Como diagnóstico inicial para a aluna $A 1$, do grupo $\mathrm{G} 2$, em relação aos conhecimentos em Geometria apontados nos PCNs (BRASIL, 1998, p. 72), identificamos que não demonstrou clareza em alguns aspectos importantes do conteúdo a ser trabalhado no sexto ano, conforme descrito e demonstrado a seguir.

Sobre o Item 5 (Cálculo da área de figuras planas pela decomposição e/ou composição em figuras de áreas conhecidas, ou por meio de estimativas.), no que diz respeito ao cálculo da área de figuras planas a aluna demonstrou não ter clareza de como fazer o cálculo, apesar de conhecer as fórmulas para calcular a área de quadrados, triângulos e retângulos. O desafio proposto a eles, ainda no Encontro 4 , foi o de construir um cercado com perímetro e área conhecidos. Os alunos precisavam descobrir que medidas deveriam ter os lados desse cercado, para que ficasse conforme especificado no relatório. Nessa tarefa, a aluna A1 sugeriu que a cerca deveria ter todos os lados com a mesma medida, demonstrando não ter clareza do procedimento que poderia ser adotado para concluir esse desafio, pois só havia feito dessa maneira, partindo da área para encontrar as medidas de figuras em formato quadrangular. A aluna sugeriu que a cerca tivesse a forma de um quadrado, pois a turma havia aprendido, há poucas semanas, o cálculo da raiz quadrada; o material didático da escola utilizava o exemplo de áreas de quadrados para descobrir a medida dos lados e a ideia da aluna foi seguir o raciocínio que já conhecia. O grupo solicitou ajuda nas primeiras estimativas com o uso do quadro branco. Depois, concluíram essa tarefa sozinhos. Dessa forma, com o auxílio da tela do Minecraft, a aluna A1 fez algumas tentativas para formar um quadrado com a área especificada no relatório, enquanto a aluna A4 fazia o mesmo processo no papel. Logo perceberam que não seria possível ter uma figura regular. Elas sabiam os valores dos primeiros quadrados perfeitos de cor, então estimaram que a medida do lado deveria ser um número um pouco menor que 10 , pois é a raiz quadrada de 100, bem próxima da área que deveriam encontrar.

Como, além da área, o perímetro também foi determinado no relatório, o grupo precisaria unir as duas informações como estratégia para vencer esse desafio. E assim fizeram: retirando e acrescentando blocos, perceberam que a figura formada poderia não ser um quadrado, mas outro quadrilátero, como o retângulo.

Assim, mostrando que o uso do jogo Minecraft no processo de ensino e aprendizagem da Geometria Espacial pode ser um agente facilitador, as alunas A1 e A4 fizeram as tentativas de construção aliando as informações de área e perímetro no próprio jogo (Figura 2), com visibilidade e percepção imediata das falhas, permitindo à aluna a correção em tempo real. 
Figura 2 - Construção de cercado como teste de medidas

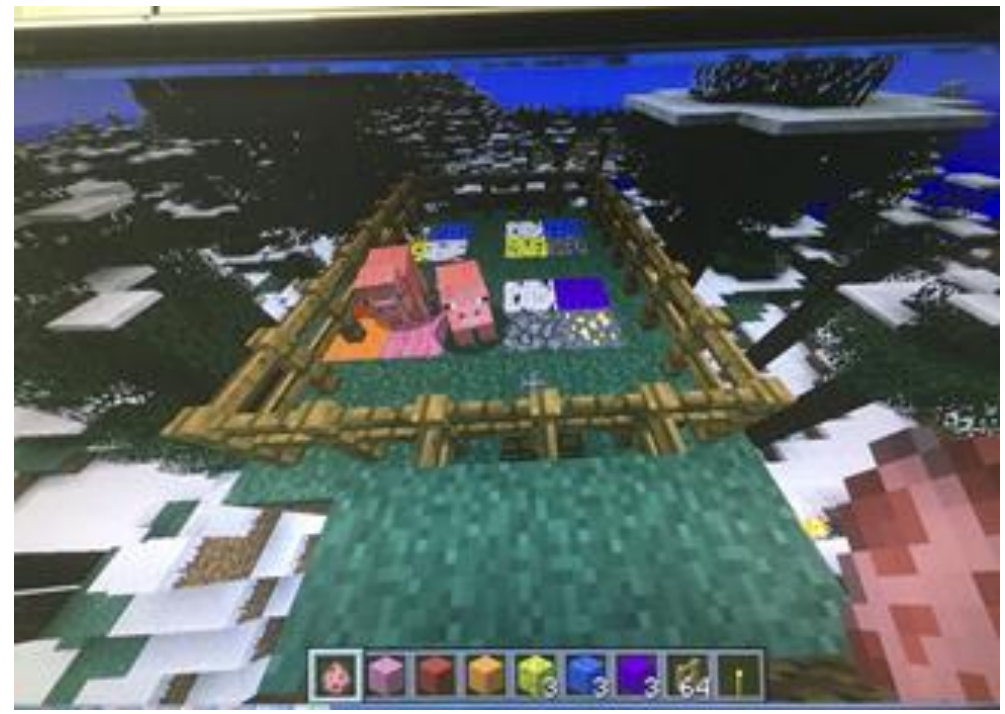

Fonte: Autores (2017).

Depois de realizada a tarefa, houve o questionamento quanto à preferência por um ou outro método para descobrir o que precisavam (Minecraft ou papel e lápis). O trecho a seguir, do Diário de Bordo, evidencia esse relato:

\footnotetext{
Perguntei a elas qual dos dois métodos foram mais vantajosos para encontrar as respostas do desafio da área e perímetro. A resposta das duas alunas veio ao mesmo tempo: "O jogo é melhor". Quando questionei o porquê, a aluna A4 disse que no papel é muito cansativo, tem que ficar calculando e é chato. A aluna $\mathrm{A} 1$ disse que conseguiu bem mais rápido que a colega, mas que precisou tentar várias vezes também (DIÁRIO DE BORDO, 03 ago. 2017).
}

Dessa forma, entendemos que a aluna A1 tenha aprendido os mecanismos que envolvem o cálculo de área de figuras retangulares, tendo como facilitador da aprendizagem a visualização imediata dos erros proporcionada pelo jogo Minecraft.

Para o aluno $A 5$, do grupo $G 1$, o diagnóstico inicial em relação aos conhecimentos em Geometria apontados nos PCNs (BRASIL, 1998, p. 72) nos permitiu identificar alguns aspectos do conteúdo pertinente ao sexto ano, em que não demonstrou clareza, conforme descrito e demonstrado a seguir.

No Item 1, que transcorre sobre distinção, em contextos variados, de figuras bidimensionais e tridimensionais, descrevendo algumas de suas características, estabelecendo relações entre elas e utilizando nomenclatura própria, durante o seminário do Encontro 2, o aluno cometeu alguns equívocos na descrição dos objetos fotografados, afirmando, por exemplo, que os bancos fixos do pátio eram formados por tampos quadrados (quando na verdade o tampo tem faces retangulares), demonstrando confusão na classificação dos quadriláteros quanto às medidas dos lados.

Isso demonstra que ainda não há clareza na distinção das formas quando o contexto é diferente do estudado em aula. Observamos, pela explicação do aluno durante sua apresentação no seminário e cuja fala está transcrita a seguir, seu cuidado em escolher formas arredondadas e formas em que apareciam ângulos retos, demonstrando que já sabia diferenciar corpos redondos e poliedros, embora 
fizesse confusão entre os elementos da geometria plana. O cuidado em retratar corpos redondos e não redondos aparece na apresentação do Seminário e está presente também no relatório do Encontro 2, quando o aluno comentou que a imagem que mais chamou a atenção foi a roda da bicicleta, porque ele não saberia dizer o nome da figura geométrica.

O aluno relatou durante esse seminário que se sentiu desafiado por não conseguir classificar o objeto "roda de bicicleta" com o que tinham estudado em Matemática. Ainda assim, ele classificou corretamente como corpo redondo, utilizando o critério curvas. De qualquer forma, o aluno não teria condições, pelo que já estudou em geometria na escola, de encaixar esse sólido nos corpos redondos estudados pela turma em anos anteriores (cone, cilindro e esfera).

Ainda, buscando efetivar uma proposta pedagógica centrada no uso de mídias digitais e jogo de computador e ainda avaliar sua viabilidade, foram promovidas ações no sentido de que o aluno percebesse que o poliedro é objeto tridimensional com características que o definem e que as figuras bidimensionais fazem parte dessa caracterização. Assim, durante os encontros que ocorreram no laboratório de informática (especialmente o Encontro 3, de exploração do Minecraft), houve uma manipulação intensa dos blocos virtuais. Os cubos foram transladados e rotacionados em diversas situações durante os encontros no laboratório de informática, capturadas de um dos vídeos em que o aluno explicou os comandos que descobriu no jogo.

Depois da manipulação virtual dos objetos tridimensionais nos encontros ocorridos no laboratório, passamos para o momento de manipulação física dos objetos. $\mathrm{O}$ aluno então deparou-se com o desafio de planificar o hexaedro. Para que a planificação fosse correta, precisaria separar suas faces. Nessa ocasião, percebemos uma mudança na fala do aluno, que demonstra ter percebido que as figuras que formam o cubo têm duas dimensões, e o objeto formado por elas possui três dimensões. Isso pode ser constatado durante o Encontro 9, na atividade de planificar o cubo, conforme relatado no Diário de Bordo:

O aluno A5, no momento da planificação do cubo [Encontro 9], teve participação decisiva na escolha da medida das arestas, mostrando aos colegas que um cubo com aresta de $4 \mathrm{~cm}$ ficaria proporcional ao tamanho do isopor disponível para construir. Com argumentos envolvendo a área a ser construída na maquete, percebi ter havido mudanças nos conhecimentos que o aluno trazia sobre faces e formatos (DIÁRIO DE BORDO, 13 set. 2017).

Ao final desse mesmo encontro, perguntei à turma, como novo desafio, se saberiam planificar outras figuras. 0 diálogo teve participação do aluno $A 5$, que afirmou ser capaz de fazer a planificação de outros objetos, alegando que seria apenas "ver que figuras formam o objeto". A fala do aluno sugere a percepção de que existem diferenças entre o que ele chama de figuras (no caso, figuras planas) e o objeto (poliedro). Entendemos que o objetivo foi parcialmente alcançado, visto que o aluno compreendeu a distinção de algumas formas geométricas em contextos diversos.

Como diagnóstico inicial para a aluna $A 8$, do grupo $\mathrm{G} 3$, em relação aos conhecimentos em Geometria apontados nos PCNs (BRASIL, 1998, p. 72), não demonstrou clareza em poucos aspectos do conteúdo a ser trabalhado no sexto ano, referente aos itens dos PCNs utilizados no contexto dessa pesquisa, conforme descrito e demonstrado a seguir. 
A respeito do Item 3 , que discute o reconhecimento de grandezas como comprimento e superfície e identificação de unidades adequadas (padronizadas ou não) para medi-las, fazendo uso de terminologia própria, a aluna demonstrou ter clareza quanto às unidades utilizadas, inclusive convertendo os blocos em centímetros quadrados, conforme a Figura 3, referente ao relatório do Encontro 5.

Figura 3 - Relatório do Encontro 5

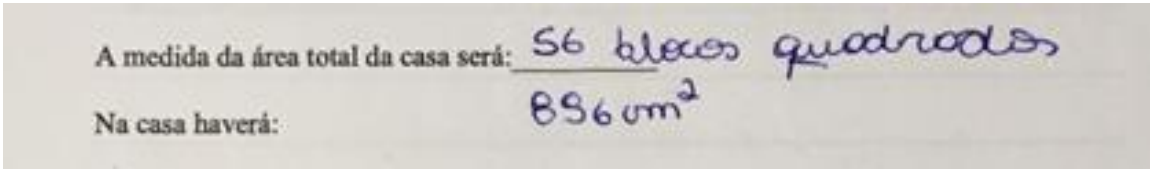

Fonte: Autores (2017).

Segundo os cálculos realizados pelos alunos do grupo G3, as medidas da casa seriam, em blocos, $7 \times 8$. A aluna então calculou a área utilizando a unidade blocos quadrados. Depois, no Encontro 10, ela complementou o relatório com a conversão da medida da área em centímetros quadrados, conforme relatado no Diário de Bordo:

Após a escolha da escala, ela fez a conversão da medida "bloco" para a medida "centímetro", pois cada bloco (na maquete) tem aresta de 4 centímetros. Assim, a área da casa em centímetros quadrados ficou em 896 $\mathrm{cm}^{2}$, conforme apontado por ela no relatório do Encontro 5. Eu não solicitei que ela fizesse isso, mas ela disse que era importante fazer a conversão de unidades para construir a maquete (DIÁRIO DE BORDO, 13 set. 2017).

O fato da aluna A8 fazer a transformação de unidades corretamente demonstra que ela tem clareza no reconhecimento das grandezas comprimento e superfície e identificação de unidades adequadas para medi-las.

Para finalizar, estes e outros dados coletados durante a sequência de atividades ilustram momentos importantes vividos durante esses quase dois meses de aplicação. A integralidade da aprendizagem dos elementos tratados nesse tempo, cujos indícios podemos verificar na análise dos dados desta pesquisa, poderá ainda ser percebida ao longo da trajetória escolar desses alunos. Elementos potencializados pelo Minecraft são pertinentes não só ao universo matemático, mas à vida de qualquer cidadão.

\section{CONSIDERAÇÕES FINAIS}

É perceptível no processo de ensino e aprendizagem de Matemática, especialmente no que se refere à Geometria Espacial, que a forma como o estudante percebe sua localização no espaço é um dos fatores determinantes para sua aprendizagem. Constatação esta, que foi uma das motivadoras da elaboração da sequência de atividades envolvendo a geometria do sexto ano, pois havia lacunas a serem preenchidas no desenvolvimento da noção espacial desses estudantes. Com isso, pretendeu-se contribuir para a melhoria no desempenho dos alunos na geometria do sexto ano e dos anos escolares subsequentes e, principalmente, contribuir na ampliação da percepção espacial desses sujeitos de maneira geral. Então, a elaboração da sequência de atividades permitiu aos alunos um contato constante com o espaço tridimensional, por meio de recursos tecnológicos como mídias digitais e o jogo de computador Minecraft, intercalados 
com o manuseio de materiais físicos que remetem ao mesmo ambiente; segundo as análises realizadas e devidamente descritas anteriormente, entendemos que $o$ objetivo foi alcançado.

Por meio das atividades propostas em cada um dos doze encontros, percebemos que alguns alunos realizaram as tarefas facilmente. Ainda assim, puderam exercitar outros elementos importantes proporcionados durante a sequência, como o respeito à opinião dos colegas e a argumentação no momento das decisões no projeto. O último encontro foi marcado pela finalização do projeto, com um seminário em que os grupos mostraram as semelhanças entre a casa construída virtualmente e a casa construída em maquete.

Nesse contexto da aplicação da sequência de atividades, especialmente em relação ao uso do Minecraft, pudemos constatar que esse jogo computacional se mostrou um importante recurso pedagógico por vários motivos. O primeiro ponto, o mais relevante, é permitir à criança a possibilidade de manipular objetos no espaço virtual, respeitando as vistas em perspectivas. Isso contribuiu com o aprendizado de geometria espacial na turma do sexto ano e a possibilidade de realizar atividades individuais e em grupos. Como segundo ponto, a facilidade de manipulação dos objetos no espaço virtual, que permite que o Minecraft seja utilizado em sala de aula como um recurso pedagógico legítimo. Pois, podem também ser trabalhadas questões de lateralidade, por exemplo, sem que o foco do trabalho seja desviado. Ainda quanto à organização espacial, testada constantemente no Minecraft, quando a tarefa proposta nos encontros foi de reproduzir esse ambiente virtual no papel, trouxe ao aluno a possibilidade de refletir sobre sua ação no jogo. Como terceiro ponto, as constantes (e muito bem divulgadas) atualizações, fazendo com que sempre haja algo novo a explorar. A quantidade de material de mídia que envolve personagens e ambiente no qual o jogo está inserido é vasta. Na internet, encontram-se tutoriais, vídeos, canais, blogs, miniaturas, revistas, histórias em quadrinhos, livros, roupas, mochilas, brinquedos e acessórios dos mais variados tipos. Ou seja, o jogo Minecraft tem a facilidade de possuir ampla divulgação, com tutoriais em vídeo, de fácil compreensão, até mesmo para quem não tem o hábito de trabalhar com jogos computacionais.

Outro ponto importante a considerar foi a atuação do professor em uma sequência de atividades em pequenos grupos com o uso do computador. Não para mostrar como resolver os desafios, mas para indicar possíveis caminhos, instigando os alunos a buscar alternativas de resolução. É importante destacar a importância de ter um material, um guia para que os grupos tenham autonomia e não dependam exclusivamente do professor para realizar as atividades. Nesta pesquisa, optou-se por imprimir relatórios com a descrição da atividade do encontro e perguntas relacionadas a ele. Os relatórios foram importantes na organização dos projetos de grupo e também na análise dos dados da pesquisa, pois trouxeram informações que não foram percebidas durante a aplicação.

Para disponibilizar a outros professores a sequência de atividades, há um material impresso em que consta essa sequência, reproduzido virtualmente em formato PDF no portal educacional online eduCAPES, sob o título "Sequência de atividades de Matemática: introdução à Geometria Espacial com o jogo Minecraft", além de um modelo de relatório, matriz para construir os cubos das maquetes, moldes de elementos do Minecraft e ainda um tutorial com os primeiros passos no jogo. 
Portanto, cumprimos com o objetivo geral de investigar as potencialidades do uso do jogo computacional Minecraft no processo de ensino e aprendizagem da Geometria Espacial em uma turma de sexto ano do ensino fundamental, bem como os objetivos específicos de discutir o uso de material concreto como elemento dos processos de ensino e aprendizagem, auxiliando na fixação da transição da ideia de objeto concreto para abstrato. Além de investigar produções científicas que contemplem o uso de jogo computacional na educação matemática, elaborar e efetivar uma proposta pedagógica centrada no uso de diferentes mídias digitais e jogo de computador, trabalhar com a construção de uma cidade virtual geometrizada, construir maquetes baseadas em modelos virtuais, avaliar a viabilidade da proposta pedagógica e verificar indícios de aprendizagem. Conforme a análise dos dados coletados e registros feitos durante a aplicação da sequência, podemos concluir que ocorreram indícios de aprendizagem, pois os objetivos propostos foram alcançados, em especial, o potencial educacional do Minecraft. Papert, Freire e Borba - autores escolhidos para discutir informática neste artigo - apontam o papel importante das tecnologias digitais. Portanto, este trabalho evidencia que o Minecraft pode se juntar a estudantes, professores, materiais concretos e outros atores como um importante aliado no processo de ensino e aprendizagem da Geometria Espacial no sexto ano do ensino fundamental. 


\title{
MINECRAFT GAME AS AN ALLY IN THE TEACHING AND LEARNING PROCESS OF SPATIAL GEOMETRY
}

\begin{abstract}
This article aims to discuss the potential of the digital game as a strategy for teaching and learning of introductory elements of Spatial Geometry in the sixth grade of Elementary School. For this research, we used, as a theoretical contribution, the Constructionism of Seymour Papert (1985), as well as the problematizing dialogue and contextualization of knowledge defended by Paulo Freire (1996). That way, a sequence of activities organized in twelve meetings was developed, adding the technology of the game Minecraft allied to other media and elements usually used. The action research is done with an analysis of collected data: Logbook, transcription of dialogues, photos, videos and the reports answered by the students. The evaluation of the relevance of this pedagogical initiative occurred based on these reviews. As a result, the research has shown its relevance to the learning of geometry, in addition to being relevant in terms of participation and commitment of the class, opening a channel of dialogue between the teacher and students.
\end{abstract}

KEYWORDS: Minecraft. Spatial Geometry. Constructionism. Problematizing Dialogue. Contextualization of Knowing. 
BORBA, M.C.; VILLARREAL, M.E. Humans-with-Media and The Organization of Mathematical Thinking: information and communication technologies, modeling, experimentation and visualizations. New York, Springer, 2005. v. 39

BRASIL. Parâmetros Curriculares Nacionais. Brasília, DF: Secretaria de Educação Fundamental, 1998.

FREIRE, P. Pedagogia do oprimido. 14 ed. Rio de Janeiro: Paz e Terra, 1985.

Pedagogia da autonomia. São Paulo: Paz e Terra, 1996.

Pedagogia da indignação: cartas pedagógicas e outros escritos. São Paulo: Ed. da Unesp, 2000.

FREIRE, P.; SHOR, I. Medo e Ousadia: o cotidiano do Professor. 8 ed. Tradução Adriana Lopez. Rio de Janeiro: Paz e Terra, 2000.

NACARATO, A. M.; SANTOS, C. A. Aprendizagem em Geometria na educação básica: a fotografia e a escrita em sala de aula. Belo Horizonte: Autêntica, 2014.

PAPERT, Seymour. LOGO: Computadores e Educação. São Paulo: Brasiliense, 1985.

SKINNER, B. F. Tecnologia do ensino. Tradução Rodolpho Azzi. São Paulo: Herder. Ed. da USP, 1972.

ZABALZA, M. A. (2004). Diários de aula: um instrumento de pesquisa e desenvolvimento profissional. Porto Alegre: Artmed. 
Recebido: 01 mai. 2019.

Aprovado: 18 mar. 2020.

DOI: $10.3895 /$ rbect.v13n3.9947

Como citar: BOITO, P.; SILVA, J. T. Jogo Minecraft como aliado no processo de ensino e aprendizagem da geometria espacial. Revista Brasileira de Ensino de Ciência e Tecnologia, Ponta Grossa, v.13, n. 3, p. 75-

92, set./dez. 2020. Disponível em: <https://periodicos.utfpr.edu.br/rbect/article/view/9947>. Acesso em: XXX.

Correspondência: Paula Boito - paulinhaboito@gmail.com

Direito autoral: Este artigo está licenciado sob os termos da Licença Creative Commons-Atribuição 4.0

Internacional. 